\title{
The Unificatory Power of Scientific Realism
}

\author{
Seungbae Park \\ Ulsan National Institute of Science and Technology
}

BIBLID [0873-626X (2017) 44; pp. 59-73]

\begin{abstract}
The no-miracles argument (Putnam 1975) holds that science is successful because successful theories are (approximately) true. Frost-Arnold (2010) objects that this argument is unacceptable because it generates neither new predictions nor unifications. It is similar to the unacceptable explanation that opium puts people to sleep because it has a dormative virtue. I reply that on close examination, realism explains not only why some theories are successful but also why successful theories exist in current science. Therefore, it unifies the disparate phenomena.
\end{abstract}

\section{Keywords}

Naturalism, no-miracles argument, scientific realism, success of science, unification.

\section{Overview}

The aim of this paper is to refute Greg Frost-Arnold's (2010) criticism of Hilary Putnam's (1975: 73) no-miracles argument for scientific realism, the view that successful theories are (approximately) true. Frost-Arnold claims that the no-miracles argument is unacceptable because it yields neither new predictions nor unifications. I argue that realism explains not only why some theories are successful but also why successful theories exist in current science. Therefore, the no-miracles argument unifies the disparate explananda.

A successful defense of the no-miracles argument means that theoretical knowledge is possible, i.e., that we can have knowledge about unobservables, such as quarks, black holes, and gravitational waves. There are, however, many other objections to the no-miracles argument, and this paper focuses on Frost-Arnold's objection,

Disputatio, Vol. IX, No. 44, May 2017

Received: 01/01/2017 Revised: 17/03/2017 Accepted: 02/05/2017 
so it does not claim that theoretical knowledge is possible. It only claims that Frost-Arnold's objection to the prospect of theoretical knowledge is surmountable.

\section{Frost-Arnold's criticism}

Putnam claims that realism "is the only philosophy that doesn't make the success of science a miracle" (1975: 73). His idea is that it is an acceptable explanation that science is successful because successful theories are true, whereas it is an unacceptable explanation that science is successful because miracles have occurred. Thus, realism best explains the success of science. This argument for realism is called the no-miracles argument. It is regarded as the strongest argument for realism in the literature.

Frost-Arnold objects that realism is unacceptable because "realism neither makes new predictions nor unifies previously disparate claims" (2010: 47). On his account, realism would be acceptable, if it explains additional phenomena, but it does not. His objection to realism accords with naturalism, which maintains that we should impose a scientific standard on a philosophical hypothesis. Thus, a philosophical hypothesis would be worthy of our credence, if it has virtues that a good scientific hypothesis exhibits, such as simplicity, independent testability, predictive power, and unificatory power.

Scientists and philosophers alike regard the explanation as unacceptable that opium puts people to sleep because it has a dormative virtue. This explanation is inadequate because it neither predicts new phenomena nor unifies disparate phenomena. An adequate hypothesis about opium should predict or explain new phenomena, phenomena other than the explanandum that it puts people to sleep. Analogously, realism should predict or explain new phenomena, phenomena other than the explanandum that science is successful, in order to be acceptable. Since it does not, it is unacceptable (FrostArnold 2010: 47-48).

What does it mean to say that a theory unifies phenomena? FrostArnold (2010: 37) cites Margaret Morrison who claims that unification occurs when a theory "can predict/explain unexpected phenomena" (Morrison 1990: 322). When a theory predicts or explains unexpected phenomena, it unifies the unexpected phenomena with 
the phenomena which the theory was originally designed to explain. Frost-Arnold (2010: 38) uses Newton's theory of motion to illustrate the concept of unification. Before Newton, people believed that the motion of planets and the free fall of objects near the earth's surface were disparate phenomena, governed by different laws of nature. With Newton's explanation, people came to think of them as related. In that sense, Newton's theory of motion unified the terrestrial and celestial phenomena.

Frost-Arnold's bases his criticism of realism on an interpretation of the no-miracles argument which holds that it is distinct from scientists' arguments for successful theories. Although this interpretation is the standard one, it is not the only one in the literature. An alternative interpretation (Park 2016a: 48-49) holds that the nomiracles argument is nothing but a succinct summary of scientists' arguments for successful theories, i.e., that the former is reducible to the latter. If this alternative interpretation is correct, Frost-Arnold's criticism does not even have a chance to get off the ground. This paper, however, puts the alternative interpretation aside and operates under the standard interpretation of the no-miracles argument.

\section{Critical response}

What are we to make of Frost-Arnold's criticism of the no-miracles argument? Admittedly, the no-miracles argument attempts to explain the success of science. However, the phrase 'the success of science' is ambiguous, as K. Brad Wray (2007: 83) aptly points out. It means that some theories are successful, but also that there are successful theories in current science. It is one thing to ask why some theories are successful; it is quite another to ask why they exist today. The first question can be answered by invoking a common semantic property that enables the successful theories to be successful, whereas the second question can be answered by depicting the historical process that produces the successful theories.

Putnam's (1975: 73) explanation of the success of science answers the question of why some theories are successful. What does it mean to say that a theory is successful? Larry Laudan says that "a theory is successful if it makes substantially correct predictions, if it leads to efficacious interventions in the natural order, if it passes a battery of 
standard tests" (1981: 23). The special theory of relativity, for example, led to an efficacious intervention, as physicists relied on it to make an atomic bomb. On Putnam's account, it would be a miracle for it to be used in this way, and yet false, so that mass is not convertible to energy as the theory says it is. This explanatory scheme also applies to the success of other theories, such as the kinetic theory of heat and the germ theory of diseases. In short, Putnam argues that we can make predictions, explanations, and manipulations by using some scientific theories because they are true.

In contrast, Bas C. van Fraassen's (1980: 40) evolutionary explanation of the success of science answers the question of why there are successful theories in current science, such as the special theory of relativity and the kinetic theory of heat. He maintains that once scientific theories are born, they are brought to the arena of tough competitions. In this arena, theories compete with one another for existence. Successful theories survive, and unsuccessful ones die:

For any scientific theory is born into a life of fierce competition, a jungle red in tooth and claw. Only the successful theories survivethe ones which in fact latched on to actual regularities in nature. (van Fraassen 1980: 40)

On this account, scientific theories are analogous to organisms in that they go through a process of natural selection. Natural selection is responsible for the existence of successful theories in current science, just as it is responsible for the existence of organisms in current ecological systems.

Putnam's and van Fraassen's explanations cover different explananda, so they are not rivals to each other, even though they are widely regarded as rivals to each other in the literature. Saying that the evolutionary explanation undermines the realist explanation because the former is an alternative to the latter is just as absurd as saying that the germ theory of diseases undermines the Big Bang theory because the former is an alternative to the latter. Therefore, realists do not have to demonstrate the superiority of Putnam's explanation to van Fraassen's explanation.

When Putnam (1975: 73) constructed the no-miracles argument, his intention was not to explain why scientists had successful theories in their hands but to explain why some theories were successful. 
Thus, realism can be said to unify disparate phenomena, once it is shown that it also explains why successful theories exist in current science.

Realism yields such an explanation (Park 2015: 23-24). It holds that scientists have successful theories today because they have retained true theories and discarded false theories. For example, the general theory of relativity exists today because scientists have retained true theories. By contrast, the cold fusion theory perished because scientists discarded false theories. According to the cold fusion theory, nuclear fusion can occur not only at high temperature but also at room temperature. It was proposed in the late 1980s and quickly discredited because experimental results disconfirmed it. On the realist account, there is a statistical correlation between retaining true theories and successful theories, meaning that if scientists keep true theories, it is likely that they will end up having successful theories in their hands. There is also a statistical correlation between discarding false theories and unsuccessful theories. Thus, the hypothesis that scientists retain true theories and discard false theories explains why successful theories exist and why unsuccessful ones perish. Note that the realist semantic property, truth, figures in the explanans. So this hypothesis is available to realists, but not to antirealists, those who only believe that a successful theory is empirically adequate.

Let me add that the preceding realist proposal does not beg the question against antirealists because it does not entail that scientists know which theories are true and which theories are false, and that they intentionally choose true theories over false theories. Scientists only choose some theories and discard others, depending on whether they are successful or not. Even so, they can acquire true theories. Only the statistical correlation between successful theories and true theories is required for scientists to acquire true theories. In other words, if scientists select theories on the basis of whether they are successful or not, they will end up possessing true theories, although they might or might not be aware that they acquire true theories.

If the preceding realist account is tenable, realism unifies the success of some theories and the existence of successful theories, i.e., it illuminates the hidden mechanism that underlies the fact that some theories are successful and the fact that successful theories exist in 
current science. For example, the special theory of relativity and the kinetic theory of heat make true predictions, and they exist in current science. Truth underlies their success and existence.

How would antirealists respond to my contention that realism explains not only the success of some theories but also the existence of successful theories? I present their possible objections and realists' replies to them in the next section.

\section{Objections and replies}

\subsection{Classic criticisms}

Antirealists would likely invoke the classic criticisms against realism, including the following notable ones: Since past theories were thrown out, present theories will also be thrown out (Poincaré 1905/1952: 160; Mach 1911: 17; Laudan 1977: 126; Putnam 1978: $25)$. Inference to the best explanation is a problematic rule of inference (van Fraassen 1989: 142-146). The success of science does not stand in need of explanation (Hendry 2001: S25). These classic objections to realism could apply to my contention that truth underlies the success of some theories and the existence of successful theories.

All of these classic objections, however, are bracketed in the debate with Frost-Arnold. Recall that he rejects realism not on the grounds that it is plagued by the traditional objections to it but on the grounds that it neither makes new predictions nor unifies disparate phenomena. The aim of this paper is to refute not the classic criticisms of realism but Frost-Arnold's criticism of it. Moreover, I (2011a, 2016b, 2016c, 2017) criticized the pessimistic induction, I (forthcoming) criticized van Fraassen's argument against inference to the best explanation, and I (2011b: 26) criticized Hendry's contention. Unfortunately, it would take us too far astray to summarize the criticisms here.

\subsection{Scientific standard}

Antirealists might admit that the proffered unification is a sort of unification, but object that it is not the kind of unification that scien- 
tists would value. Scientists are not interested in whether realism explains only the success of some theories, or both the success of some theories and the existence of successful theories because these realist explanations are philosophical explanations of scientific phenomena and scientists are only interested in scientific explanations of natural phenomena. Even if they were interested in the realist explanations, it is not clear whether they would accept them, and hence whether they would accept the realist unification of the two explananda. Therefore, it is not clear whether realism meets a scientific standard.

My response to the foregoing antirealist objection is to investigate whether the corresponding antirealist unification of the success of some theories and the existence of successful theories meets the scientific standard that antirealists have imposed on the realist unification. There are several antirealist explanations of the success of science. I will scrutinize only the one formulated by Alan Musgrave (1988: 242) and James Ladyman (1999: 186), which holds that science is successful because successful theories are empirically adequate. So far as I can tell, this proposal is also subject to FrostArnold's criticism that it generates neither new predictions nor new unifications.

To get around this criticism, antirealists might make a move similar to the one that I made above to defend realism. That is, they might contend that antirealism explains not only why some theories are successful but also why successful theories exist in current science. On this account, a theory is successful because it is empirically adequate, and scientists have successful theories today because they have selected empirically adequate theories. Thus, the process of retaining empirically adequate theories is responsible for the existence of successful theories in current science. There is a statistical correlation between the existence of successful theories and the selection of empirically adequate theories, meaning that if scientists select empirically adequate theories, it is likely that they will end up having successful theories. Thus, antirealism, the view that successful theories are empirically adequate, unifies the disparate phenomena: the success of some theories and the existence of successful theories.

An interesting question, however, is whether this antirealist unification of the two explananda is the kind of unification that scientists would value. Scientists are not interested in whether antirealism 
explains only the success of some theories, or both the success of some theories and the existence of successful theories because these antirealist explanations are philosophical explanations of scientific phenomena and scientists are only interested in scientific explanations of natural phenomena. Even if they were interested in the antirealist explanations, it is not clear whether they would accept them and hence whether they would accept the antirealist unification of the two explananda. Therefore, it is not clear whether the antirealist unification meets the scientific standard that antirealists impose on realism.

One moral is that since philosophers and scientists are interested in different phenomena, they are interested in different unifications. Philosophers are interested in philosophical unifications of scientific phenomena, whereas scientists are interested in scientific unifications of natural phenomena. The fact that philosophers, but not scientists, are interested in philosophical unifications does not denigrate the philosophical unifications. What matters is not whether scientists would accept philosophical unifications of scientific phenomena but whether the structure of the philosophical unifications resembles that of the scientific unifications of natural phenomena. As long as they are similar, the philosophical unifications of scientific phenomena have met the requirement of naturalism that philosophy should use the same methods as science.

So far as I can tell, philosophical unifications of scientific phenomena and scientific unifications of natural phenomena are structurally similar. In both cases, a hypothesis explains phenomena previously thought of as unrelated, and as a result of the explanations, they are now thought of as related. Hence, the hypothesis unifies the disparate phenomena. There is no relevant difference between the philosophical and scientific unifications. Thus, instead of merely saying that the realist unification of the disparate explananda does not meet a scientific standard, antirealists should specify what exactly is defective with the realist unification. Moreover, they owe us an account of how the antirealist unification avoids the criticism that they level at the realist unification. 


\subsection{Superiority}

Antirealists might also raise the following objection. We now have the realist unification and the antirealist explanation of why some theories are successful and why they exist in current science. According to the former, truth underlies the disparate phenomena, whereas according to the latter, empirical adequacy underlies them. In such circumstances, realists have the burden to show that the realist unification is better than the antirealist unification. After all, the no-miracles argument claims that realism best explains the success of science.

This challenge is legitimate. Let me say, however, that the aim of this paper is not to demonstrate the superiority of realism over antirealism but to refute Frost-Arnold's criticism against realism. His criticism is not whether the realist unification is better than the antirealist unification but rather whether realism makes a unification of disparate phenomena. Thus, the realist unification of the two disparate phenomena refutes his criticism, regardless of whether it competes with the antirealist unification and whether the former is superior to the latter.

In Section 4.1, I briefly introduced some classic criticisms against realism. To be fair, I should do the same thing to antirealism. Let me briefly introduce some standard objections to antirealism. The antirealist suggestion that a theory is successful because it is empirically adequate is similar to the suggestion that "some crows are black because all crows are" (Musgrave 1988: 242), and generalizations "do not explain their instances" (Leplin 1997: 23). Furthermore, antirealism falls prey to the pessimistic induction that past theories turned out to be empirically inadequate, so present theories will also turn out to be empirically inadequate (Park 2001: 78; Lange 2002: 282; Lyons 2003: 898). Antirealism is also susceptible to the criticism that the success of science does not need to be explained (Hendry 2001: S25).

\subsection{Different explanantia}

Antirealists might object that there are two realist explanations of why some theories are successful and why successful theories exist 
in current science. These explanations invoke different explanantia, and hence it is problematic to say that realism unifies the two explananda. Consider the following two realist explanations:

$\left(S_{1}\right)$ Some theories are successful because they are true.

$\left(\mathrm{S}_{2}\right)$ Scientists have successful theories because they selected true theories.

The explanans of $\left(\mathrm{S}_{1}\right)$ is the hypothesis that successful theories are true, and that of $\left(\mathrm{S}_{2}\right)$ is the hypothesis that scientists selected true theories. The two explanantia differ from each other. Moreover, the explanans of $\left(\mathrm{S}_{2}\right)$ cannot explain the explanandum of $\left(\mathrm{S}_{1}\right)$. For example, the general theory of relativity makes true predictions about black holes and gravitational waves. It is problematic to say that the general theory of relativity makes true predictions because scientists selected it, given that scientists' selecting it is not the cause of its making true predictions. By contrast, it is unproblematic to say that scientists selected it because it made true predictions. In sum, I have provided the two hypotheses, when I should have provided one hypothesis to explain the two disparate explananda. Therefore, no unification is achieved by realism.

This criticism, however, stems from a failure to analyze the explanans of $\left(\mathrm{S}_{2}\right)$ more closely. The explanans of $\left(\mathrm{S}_{2}\right)$ is nothing but the conjunction of the following two claims:

$\left(E_{1}\right)$ Successful theories are true.

$\left(\mathrm{E}_{2}\right)$ Scientists selected successful theories.

If successful theories are true, and if scientists selected successful theories, it necessarily follows that scientists selected true theories. Note that $\left(\mathrm{E}_{1}\right)$ coincides with the explanans of $\left(\mathrm{S}_{1}\right)$, and that the explanans of $\left(\mathrm{S}_{1}\right)$ is exactly what realism claims. Thus, realism can be found both in the explanans of $\left(\mathrm{S}_{1}\right)$ and in the explanans of $\left(\mathrm{S}_{2}\right)$.

What, then, are we to make of $\left(\mathrm{E}_{2}\right)$ ? My answer is that it is an initial condition. It is needed for $\left(E_{1}\right)$ to entail the explanandum that scientists have successful theories. The explanandum is a claim about what scientists do. However, $\left(\mathrm{E}_{1}\right)$ does not make any claim about what scientists do. So it alone cannot entail the explanandum. It 
needs to be supplied with $\left(\mathrm{E}_{2}\right)$, which is a claim about what scientists do.

Different initial conditions are required for a scientific theory to explain different phenomena. For example, the initial condition required for Newton's theory of motion to explain the motion of a pendulum differs from the initial condition required for it to explain the motion of a planet. The set of explanantia explaining the motion of a pendulum is different from the set of explanantia explaining the motion of a planet because they include different initial conditions. But the different sets do have a common member, viz., Newton's theory of motion. It follows that Newton's theory of motion unifies the motion of a pendulum and the motion of a planet. Similarly, realism unifies the success of some theories and the existence of successful theories, even if the set of the explanantia explaining the success of some theories is different from the set of the explanantia explaining the existence of successful theories, because the two different sets have a common member, viz., realism.

Suppose, for the sake of argument, that the explanans of $\left(\mathrm{S}_{2}\right)$ cannot be divided into $\left(E_{1}\right)$ and $\left(E_{2}\right)$, contrary to what I suggested above. In that case, antirealists might argue that the explanantia of $\left(\mathrm{S}_{1}\right)$ and $\left(\mathrm{S}_{2}\right)$ are different from each other, and hence that realism does not unify the two disparate phenomena. This objection, however, would destroy not only the realist unification but also the antirealist unification sketched in Section 4.2. The antirealist explanations invoke different explanantia. The first explanans is the hypothesis that successful theories are empirically adequate, and the second explanans is the hypothesis that scientists select empirically adequate theories. The second explanans explains why scientists have successful theories, but it cannot explain why some theories are successful. It is wrong to say that some theories are successful because scientists have selected empirically adequate theories. Scientists' selecting empirically adequate theories is not the cause of the theories' making true predictions. Rather, their making true predictions is the cause of scientists' having selected them. In short, antirealists have provided two antirealist hypotheses, when they should have provided only one hypothesis, to explain the two disparate explananda. Therefore, no unification has been achieved by antirealism. Antirealists should always be mindful that their criticisms against realism might backfire 
on their own positions.

\subsection{Further objections}

I claimed above that realism explains the two disparate phenomena: some theories are successful, and they exist in current science. The explanations hold that some theories are successful because they are true, and that they exist today because scientists selected true theories. One may object that it is not clear whether the two phenomena are in fact disparate.

Let me use an analogy to clarify the difference between the two phenomena. Consider that human beings can make complex things, such as computers and electron microscopes. It is one thing to ask why human beings have the capability; it is another to ask why human beings having the capability exist. A possible answer to the first question is that human beings are intelligent. A possible answer to the second question is that their ancestors formed a society in which intelligence was required to do well in the battle to deceive others and to avoid being deceived by others. Similarly, it is one thing to ask why some theories are successful; it is another to ask why they exist. Realists' answer to the first question is that they are true, and their answer to the second question is that scientists' selected true theories.

One may raise another objection. It is realists who initiated the task of explaining the success of science. So if their own alleged explanation fails to meet the scientific standard that a hypothesis should yield new predictions or unifications, realists look much worse than antirealists.

I insist, however, that realists are not worse off than antirealists. Realists explain the success of some theories by saying that they are true. They take the success of the theories to be the evidence for the realist belief that they are true. By contrast, antirealists explain the success of some theories by saying that they are empirically adequate. They take the success of the theories to be the evidence for the antirealist belief that they are empirically adequate. Now, if the realist explanation is unacceptable because it does not meet the scientific standard, the antirealist explanation is also unacceptable because it does not meet the scientific standard either. If the realist explanation 
is unacceptable, realists lose the justification for the realist belief that successful theories are true. Similarly, if the antirealist explanation is unacceptable, antirealists also lose the justification for the antirealist belief that successful theories are empirically adequate. As a result, both the realist belief and the antirealist belief become unwarranted. It is not the case that the realist belief becomes unwarranted, whereas the antirealist belief remains warranted. Therefore, antirealists are no better off than realists.

\section{Conclusion}

To summarize, Frost-Arnold objects that the realist explanation of the success of science is inadequate because it generates neither new predictions nor unifications. I replied that on close examination, realism explains not only why some theories are successful but also why successful theories exist in current science. The no-miracles argument was designed by Putnam to explain why some theories are successful, but not why successful theories exist in current science. Therefore, it makes a novel explanation and unifies the disparate phenomena.

Let me remind readers that this paper started with the assumption that the standard interpretation of the no-miracles argument is correct, and hence that the no-miracles argument is separate from scientists' arguments for successful theories. However, suppose the standard interpretation is incorrect, and the no-miracles argument is nothing more than a shorthand for scientists' arguments for successful scientific theories. In that case, to say that the no-miracles argument does not unify disparate phenomena amounts to saying that successful scientific theories do not unify disparate phenomena, which is clearly false. This line of undermining Frost-Arnold's objection to realism can be pursued on a future occasion. ${ }^{1}$

Seungbae Park Division of General Studies Ulsan National Institute of Science and Technology 44919 Ulsan, Republic of Korea nature@unist.ac.kr

\footnotetext{
${ }^{1}$ I thank anonymous referees of this journal for useful comments.
} 


\section{References}

Frost-Arnold, Greg. 2010. The no-miracles argument: inference to an unacceptable explanation. Philosophy of Science 77 (1): 35-58.

Hendry, Robin. 2001. Are realism and instrumentalism methodologically indifferent? Philosophy of Science 68 (Proceedings): S25-S37.

Ladyman, James. 1999. Review of Leplin's A Novel Defense of Scientific Realism. The British Journal for the Philosophy of Science 50 (1): 181-188.

Lange, Marc. 2002. Baseball, pessimistic inductions and the turnover fallacy. Analysis 62 (4): 2881-2885.

Laudan, Larry. 1977. Progress and Its Problems: Towards a Theory of Scientific Growth. California: University of California Press.

Laudan, Larry. 1981. A confutation of convergent realism. Philosophy of Science 48 (1): $19-49$.

Leplin, Jarrett. 1997. A Novel Defense of Scientific Realism. New York: Oxford University Press.

Lyons, Timothy. 2003. Explaining the success of a scientific theory. Philosophy of Science 70 (5): 891-901.

Mach, Ernst. 1911. History and Root of the Principle of the Conservation of Energy. Translated by P. E. B. Jourdain. Chicago: Open Court Publishing Company.

Morrison, Margaret. 1990. Unification, realism, and inference. The British Journal for the Philosophy of Science 41 (3): 305-332.

Musgrave, Alan. 1988. The ultimate argument for scientific realism. In Relativism and Realism in Science, edited by Robert Nola. Dordrecht: Kluwer Academic Publishers, 229-252.

Park, Seungbae. 2001. Scientific Realism vs. Scientific Antirealism. PhD Dissertation. University of Arizona.

Park, Seungbae. 2011a. A confutation of the pessimistic induction. Journal for General Philosophy of Science 42 (1): 75-84.

Park, Seungbae. 2011b. Coherence of our best scientific theories. Foundations of Science 16 (1): 21-30.

Park, Seungbae. 2015. Explanatory failures of relative realism. Epistemologia 38 (1): $16-28$

Park, Seungbae. 2016a. Extensional scientific realism vs. intensional scientific realism. Studies in History and Philosophy of Science 59: 46-52.

Park, Seungbae. 2016b. Refutations of the two pessimistic inductions. Philosophia 44 (3): 835-844.

Park, Seungbae. 2016c. Why should we be pessimistic about antirealists and pessimists? Foundations of Science. doi:10.1007/s10699-016-9490-y.

Park, Seungbae. 2017. The uniformity principle vs. the disuniformity principle. Acta Analytica 32 (2): 213-222.

Park, Seungbae. Forthcoming. Scientific antirealists have set fire to their own houses. Prolegomena.

Poincaré, Henri. 1905/1952. Science and Hypothesis. New York: Dover.

Putnam, Hilary. 1975. Mathematics, Matter and Method (Philosophical Papers, vo. 1), 
Cambridge: Cambridge University Press.

Putnam, Hilary. 1978. Meaning and the Moral Sciences. London: Routledge \& K. Paul.

van Fraassen, Bas. 1980. The Scientific Image. Oxford: Oxford University Press. van Fraassen, Bas. 1989. Laws and Symmetry. Oxford: Oxford University Press. Wray, K. Brad. 2007. A selectionist explanation for the success and failures of science. Erkenntnis 67 (1): 81-89. 